\title{
The teaching reform of literature retrieval course based on MOOCs
}

\author{
Jingjing Xia
}

School of Education Science, Nantong University, Nantong 226001, P.R. China

Abstract- With the advancement of information and communication technology under the digital world, the limitations of the teaching mode of traditional literature retrieval course become increasingly apparent. In particular, the rise of MOOCs (Massive Open Online Courses) impacts on the traditional literature retrieval course teaching, not only forces the course teaching reform, but also provides the means and methods of reform. Transformation of teaching concept of the literature retrieval course is based on the MOOCs literature retrieval course. The evaluation mechanism, which is the possible ways for the teaching reform of literature retrieval course, based on the formation of flipping the classroom lecture mode of the teachers and students' mutual evaluation.

Keywords-improving classroom teaching, media in education.

\section{INTRODUCTION}

Literature retrieval and utilization of course not only helps to meet the needs of students of literature information and improves the teaching level, but also is the key components to education for the future development. The course hadalso been played a crucial role in promoting students to widen their sight, optimize the knowledge system, further improve the awareness of independent learning and thinking, and cultivate innovative thinking. Therefore, literature retrieval and utilization course had been developed for colleges and universities, especially for the majority of College students. This course had played a very important role in improving the information literacy of College students. But with the advent of the era of big data and the development of education technology under the network environment, making use of computer retrieval literature is getting stronger and stronger, and retrieval technology is also in constant progress. Hence, it puts forward a new challenge to the traditional teaching retrieval skills which was based on document retrieval course.

Teaching mode of the literature retrieval course should be re-established in the network environment on the basis of the aforementioned facts. Scholars have reached a consensus that the realization of teaching goal must be changed from traditional retrieval to information literacy skills type. So, how to achieve this change? The authors believe that the rise of MOOCs not only forces the reform of traditional literature retrieval course, but also provides the means and methods of reform. Based on this, this paper intends to explore the traditional literature retrieval curriculum reform based on the teaching methods and means from the perspective of MOOCs.

\section{ANALYSIS OF LIMITATIONS FOR THE TRADITIONAL MODES OF DELIVERY}

The traditional literature retrieval teaching adopts the centralized teaching mode, which is divided into three parts: teaching, practice and examination. Most colleges and universities focus on 16,24 , or 32 hours of teaching in one semester of the learning process. During the traditional teaching mode, the teacher is at the center of teaching and learning process, in which they focus more on the concept of literature retrieval and related retrieval practices of 
teaching and interpretation.

The most obvious disadvantage, which is embodied in the students, is always in the non-active role of the recipient, but not the ability to optimize the reception to improve the students' learning autonomy, professional knowledge collection and filing and students' information consciousness and the proper operation of information technology. At the end of the course, the students just mastered some of the most popular literature information retrieval technology based on the collocation of the search words, but they don't have obvious improvement in the perception of information, attention, thinking and method of adjusting the systematic, targeted, consciously obtaining useful information to make better able to accept knowledge. It is impossible to reflect the advantages of the literature retrieval course to cultivate the information literacy of University students due to its several advantages. Though, the limitations are as follows:

Firstly, the design of literature search is out of touch with the student's professional knowledge, it can't inspire the students' learning interest and cultivate the consciousness of self-learning. In the University, its literature retrieval course is an independent curriculum, but itself does not closely combine with students' professional knowledge, majority of the students can't understand exactly what is expected to set up such courses, so they define it as lower credit hour course, and do not give enough attention. Usually, different professions in the college have different kinds of literature retrieval teaching materials, and thus have their own distinct emphasis. Although, the teachers choose different retrieval tools and reference books according to the professional needs, but still can't link it to their own professional courses, at the same time, because of the teaching content do not have reasonable settings. Moreover, most teachers are not library science professionals, which lead to lack of relevant professional knowledge reserves and shortage of certain skills in the teaching process. Therefore, it is not feasible to make students more active to search the relevant professional knowledge, and thus can't effectively attract students to further exploration. Students can't be practical to strengthen their subjective initiative and to explore the power of understanding unless the learning and teaching effect should be guaranteed to a certain extent. Therefore, this kind of typical teaching model can't effectively improve and enhance the students' information literacy to a certain extent.

Secondly, students are not trained with the ability of information retrieval and cultivated with the ability of using information. The former is focused more on the information retrieval and the latter is focused more on the use of information. Because there are certain constraints in the way that we have focused our lectures, in relatively limited time, the students can't effectively enhance and improve their retrieval and operation ability. This also can't be used in making the rest of the opportunity to further improve the operation ability of information, and the actual arrangement of the teaching of information retrieval course in quite a long period. In the content related information about the use of never concerned about, which led to the college students in our country can't reasonably use information under certain conditions, at the same time, the lack of independent innovation spirit of complete and scientific research ability to further resolve a problem. However, based on the information from the point of view of further analysis, the use of information result is closely related to its value in a certain extent. Besides, only accepting information input is not feasible to use information of people to a certain extent, can't be called a real person can reasonably control information.

Thirdly, students are not trained with information knowledge, retrieval methods and also cultivated with the awareness of information. From first to last, literature retrieval course is regarded as a course which can teach students how to effectively search for information. It belongs to a kind of skill in which oriented to a group of students to a certain extent. As long as it is operated 
reasonably, it can generate a good result. University is the essence of literature retrieval course where enables the students to have pertinence and the skills to explore and forecast planning and access to information. This is to make them better able to frontal study a series of basic specialized knowledge and a certain analysis and research.But when most students are at the end of this course of information collection, they have not yet achieved obvious improvement and optimization in gathering and analyzing information, as well as using information in terms of accuracy and initiative. The reason for this situation is that the first phase of the literature retrieval course is only concerned about the information and the relevant knowledge of the specific mode of operation and explanation, but did not focus on training students' information awareness. Only relying on the limited class hours in the classroom is not a sense of information, we should form a habit of thinking in the study and life, and constantly to strengthen it through practice.

Only the training of skilled talents is the retrieval of the traditional literature retrieval course, and can't meet the demands of contemporary quality education, to achieve the overall teaching goal of cultivating students' information literacy.It is necessary to reform the traditional teaching mode, explore a new model to adapt to the needs of the current generations. The rise of the MOOCs has a very significant inspiration towards the traditional literature retrieval course teaching reform.

\section{Overview of MOOCs}

MOOCs is a Massive Open Online Courses, also translated as "Mu class" or "grinding division". The MOOC teaching format has its roots in the philosophical approach of the Open University and the technological platform of traditional online courses. Canadian educators Stephen Downes and George Siemens, both of the University of Manitoba, are credited for introducing the first predecessor to today's MOOC, with their 2008 open online course titled “Connectivism and Connective Knowledge/2008 (CCK08).
In the autumn of 2011, the course, Introduction to Artificial Intelligence created by Sebastian Thrun, a Stanford roboticist and a cooperative professor, Peter Norvig, received an enrollment of 160,000 people, with students spreading all over the world,It is known as the biggest innovation since the invention of printing education. From 2013 onwards, the Peking University, Tsinghua University and other universities have joined the "Mu" platform, the localization of $\mathrm{Mu}$ class alliance platform began construction. It covers the fields of natural science, social science and humanities. Compared with the traditional teaching methods, MOOCs has its own advantages and characteristics.

Firstly, the transparency and fairness of a class. Online courses face global students' need to withstand market considerations and choices, teaching quality assessment in a free market environment to become simple and fair. Online courses allow the quality of courses and teaching in a university is no longer a single campus thing, and become transparent on a global scale. In a sense, it reflects a certain degree of justice.

Secondly, the course is open. At present, in the Midwest Chinese and vast rural areas, the education system and teaching content are obsolete. In most cases, the lack of complete first-class team of teachers and improvementin the system of teaching skills are responsible. Most of the first-class educational resources are gathered in the eastern part of the country, as well as in the more developed cities and related areas. Therefore, the promotion of MOOCs will play a crucial role in the proper coordination of the issue of the education fairness in China, which has a wide area and a large population.

Thirdly, the teaching model for the Internet online courses. People are not confined to a certain location, instead computers and network connection can be localized. No matter where you can spend the least money to enjoy the best courses in American universities, teachers are no longer confined to a single direction. Previously, students 
would like to explain knowledge, but to a certain extent, giving students some guidance and inspiration, will allow students to become the masters of teaching and learning process.

MOOCs have been the most popular in the past few years because of the idea of promoting the overall quality of education resources and the concept of global sharing. "NMC horizon report: 2013 Higher Education Edition" has reported that MOOCs has a very significant impact on the future of online learning. As a new teaching mode, MOOCs will bring significant impact on the traditional literature retrieval course, and will also provide useful enlightenment to the reform of the traditional literature retrieval course.

\section{A DESIGN OF LITERATURE RETRIEVAL COURSE TURNOVER BASED ON MOOCS}

With its unique characteristics and advantages, MOOCs will bring different development concepts and operating mechanism to the literature retrieval course, and will encounter a series of opportunities and challenges.To properly use this platform, teachers of literature retrieval, should optimize the literature retrieval course teaching process. The authors pay more attention to the interoperability and pertinence of educational resources andcontinue to optimize the teaching design of the course of literature retrieval. The process of implementing the teaching plan can be carried out for the purpose of the literature retrieval course based on MOOCs inversion of the following case designs.

\subsection{Instructional objectives}

Through a comprehensive assessment of the ability of using information retrieval task, the students will study the information source, flexible mode of operation, retrieval, retrieval strategy, comparative analysis, using the adjustment and re-adjustment. These will enable students to finally form a sound system of retrieval process, thus further strengthen the practical technology of information retrieval.

\subsection{Content of courses}

First of all, the members of the team query system, after the manual lending through the public order and topic direction related three books, would fill in the title, classification number, author, publisher and publishing year of the library. The students make the research content through the analysis of the topic, and determine the key words in English and Chinese and English logic retrieval expression through the refining of the main technical points of the project. Secondly, the team will select the search tool; search, record, collate the results of the search, according to the above documents; compose the literature retrieval analysis; encourage members of the reporting team to present the difficulties that encountered in the literature retrieval process; and the various retrieval results. On the other hand, students of the reporting team would answer the questions, and then the teacher has a further explanation on the common problems. Finally, the student self-evaluation, the group member each other, the classroom teacher comments will be carried out.

\subsection{The teaching method}

The 36 students of material science and engineering class in Yancheng Institute of Technology College will be divided intosix groups according to the class size, in a group of six students will be able to discuss the homework and do report in the classroom. Before class, they will watch related videos of the information source on the network. In this case, the author on the basis of the fixed use of PPT courseware uses Adobe Presenter software to make electronic teaching plans and adds appropriate classroom interaction to make theoretical knowledge more vivid. Which can enable students to better grasp, set up the knowledge points of the general search method of the database, and make a 3-5-minute micro video? These will allow students to master this part of knowledge. Finally, the curriculum platform will be used to collect all the learning resources provided by teachers and the work completed by the student team to form teaching archives preservation. In 
fact, these help students to digest the classroom content and to make-up the deficiencies in time.

\subsection{Teaching evaluation}

Further analysis has shown that from the final harvest of the learning city, flipped classroom MOOCs teaching mode based on procedural knowledge construction, such as "general database retrieval skills",was very good.It can help students' further rational use of knowledge points and also contributes to the better design of interactive learning modules in the field of strategic knowledge, which can greatly improve the students' cognitive ability, whether it is the specific performance of the classroom or the final works are ideal. Most students can be aware of the current stage of learning tasks, at the same time, we can do a more in-depth study. However, there are still some students can't properly deal with learning tasks.

\section{DISCUSSION ON THE PATH OF TEACHING REFORM OF LITERATURE RETRIEVAL COURSE BASED ON MOOCS}

4.1 Discussion on the teaching idea of transforming the literature retrieval course teacher based on MOOCs

Under theenvironment of MOOCs, the teacher should set up a unique teaching method which regards students as the center.In the teaching design of literature retrieval course, we should carry out the team cooperation; absorb all the professional and relevant teaching background of teachers; coordinate with the curriculum planning; carry on reasonable team division; and strengthen the literature retrieval course teaching level together.According to the knowledge of the authorsregarding the current situation, it is known that the background of the literature retrieval course is more diversified, mainly involves computer, materials, civil engineering, chemical engineering and library science.However, it involves all the students in the whole school, and thus teachers must coordinate the work strictly according to the specific planning of the relevant courses teaching, usually need to arrange a teacher and assistant teacher. The teaching method is set up for the teachers to organize students to discuss the interactive discussion and question answers. During the whole stage of curriculum implementation, teachers are not only teaching knowledge from the direction of students, but also give the necessary guidance and planning for the learning process of students based on their own series of professional knowledge. Due to the fact that the students are not perfectly enough to be aware of their own knowledge and the related ability, they cannot be fully understood the concrete results that need to be achieved during the whole process. But through the teacher's planning advice, teachers can turn the literature retrieval classroom based on the MOOCs environment, that is, a single passive teaching knowledge into guiding students' autonomous learning, and promote students' independent development.

4.2 Process and application analysis of building document retrieval course based on MOOCs

Information literacy education is a kind of education that transforms the theoretical concept into practical operation ability.The teaching goal of document retrieval course is to train the information literacy education to cultivate the information literacy ability, which has formed a certain consensus among the teaching researchers in literature retrieval course.As a practical and operational course, the previous literature retrieval course teaching planning and methods need to be kept pace with the times and constantly adjust the actual situation. The teaching content, teaching methods and the means of teaching evaluation need to be diversified.The construction of literature retrieval course needs to be flipped classroom that is based on MOOCs, which can effectively achieve the teaching purpose of document retrieval course.

First of all, the literature retrieval teachers should further carry out the interactive evaluation of learning activities through the quantitative scoring model such as the job description, problem communication, thematic research, 
knowledge application and other aspects. It mainly involves the mutual evaluation of students and a series of guidance suggestions that the teacher gives, this can be more comprehensive and detailed understanding of the students at the present stage of learning behavior.It alsohelps students to clear and deal with the difficulties encountered in learning a series of difficult situations, thus better promote students to carry out autonomous learning; and also enable teachers in the shortest time to clear the knowledge of students, thus more conducive to the later teaching planning settings.

Secondly, duringthe process of implementation in student interaction evaluation and the interaction between the team, teachers need to display a clear evaluation rubric in the classroom, by looking for the retrieval database as a practical example. (1), from the completion of the work (whether the topic is reasonable, not limited and has a certain innovation, with a certain timeliness and relatively comprehensive content); (2), from the flexible use of the knowledge theory of learning (involving the selection of database precision and detailed adjustment of different retrieval methods can flexibly use different key retrieval methods); (3), from the exhibition report (mainly involves the uniqueness of the display method of works, the rationality of language expression, accuracy, orderly and can make good interaction with the audience and actively answer a series of questions), and (4) publish the proportion of the score. This can effectively deal with the students' evaluation because of their own personal color is too serious which makes the final evaluation unfair and cannot reflect the actual situation. Therefore, practical guidance and a certain role in prompting students can ensure the evaluation process to be carried out smoothly.

Thirdly, in the students' performance evaluation, the traditional score should be replaced by grade score, since score evaluation is not the final goal, but alsoit is an effective way to improve the students' information literacy ability.The essence of this evaluation is to promote the evaluation of learning, which is also a standard evaluation, because the literature retrievalbased on MOOCs is not reasonable in a group. Hence, students can meet the requirements of curriculum standard, and get better in "learning interest","learning habit" and" academic achievement", and thuseveryone can be excellent.

\section{OUTLOOK FOR THE FUTURE}

The construction of document retrieval flipped classroom based on MOOCs is a new teaching idea and teaching method.In this mode, the literature retrieval classroom becomes the place where the students interact, collaborate and construct ideas in order to develop and enhance the students' cooperative communication ability, knowledge exploration ability and application implementation ability.This is exactly the part that needs to be incorporated and adjusted in the literature retrieval teaching and even the whole higher education.Admittedly, due to the objective reasons of various aspects, the application of literature retrieval course teaching based on MOOCs needs literature retrieval teachers and researchers to try and grope in the real teaching practice, and to innovate and improve gradually.

\section{REFERENCES}

[1] MOOC [EB/OL]. [2014-05-15]. http: //en.wikipedia.org /wiki /MOOC.

[2] Hong Qin. The rise of moo and the role of library [J. Journal of library science in China, 2014 (2): 19-26.

[3] Bo Luo. A review of the role of massive online open courses (MOOCs) and university library [J] .Library and information work, 2014, 58 (3) : 130-136.

[4] Xiaojuan Zhang, Hanlu Zhang, Yushan Fan, and so on. The basic mode of information literacy education in colleges and universities and the practice research at home and abroad $[\mathrm{J}]$. Journal of academic libraries, 2012(2): 95-101. 
[5] Fengfeng Liu. Information literacy education in colleges and universities under the environment of massive open online course [ J ] Intelligence exploration, 2015(3).

[6] Things You Should Know About Flipped Classrooms [EB/OL]. [2012-08-20]. http://net.educause.edu/ir/library/pdf/ELI7081.pdf.

[7] Xiaoying Zeng. Introduction of PBL teaching model in literature retrieval course $[\mathrm{J}]$. shanxi library journal, 2009(4):21-23

[8] Shuqiong Yang. On the teaching of information retrieval course based on collaborative learning $[\mathrm{J}]$. Library science research, 2005(8):67-70.

[9] Claudia W. Scholz. MOOCs and the Liberal Arts College $[\mathrm{J} / \mathrm{OL}]$. Journal of Online Learning and Teaching, 2013, 9(2) : 249-260. [2015 - 01 20 ]. http: / /jolt . merlot. org /vol9no2 /scholz_0613. pdf.

[10] Tuo Zhang, Yuewei Wu. The role of foreign university libraries in MOOCs and its enlightenment $[\mathrm{J}]$. Library construction, 2014( 7) : 85-89.

[11] Shunping Xu. Analysis of the involvement of Chinese universities and teachers in MOOCs: a case of Tsinghua university $[\mathrm{J}]$. Distance education in China, 2014(6) : 33-39, 64, 9

[12] Marques, J. (2013). A short history of MOOCs and distance learning. MOOC News\&Reviews. http://moocnewsandreviews.com/ashort-history-ofmoocs-and-distance-learning/. 